\title{
Digital Exclusion in the Labour Market in European Countries: Causes and Consequences
}

\author{
Izabela Czaja $^{1}$ and Maria Urbaniec ${ }^{2}$
}

\begin{abstract}
Changes in the labour market in Europe, as well as globally, evolve and are caused by many factors, the impact of which is difficult to predict. Technological changes, the universality of communication, and control solutions requiring new skills and advanced IT knowledge on programming of cooperating devices result in the exclusion from the labour market of people unable to handle advanced machines and devices. Accelerating technological changes may increase the number of those excluded. The purpose of this article is to identify the causes and effects of technological exclusion on the labour market in European countries. In order to achieve this research goal, a review of mainstream literature will be conducted followed by document-based research and statistical databases. The results of this analysis show that digital exclusion may result not only from lack of individual access to technology, but also from lack of skills or the ability to use technology, which leads to social exclusion or no access to jobs. This proves that attitudes towards modern technologies on the labour market in the context of finding or creating jobs and sources of income are varied and dependent on various factors.
\end{abstract}

Keywords: labour market, digital divide, digital exclusion, digital skills, causes, consequences, DESI

\section{Introduction}

Globalisation and technology give rise to changes in labour markets. New technologies replace people as part of routine tasks, eliminating some tasks and changing the scope of work of others. Global competition shifts production around the world, destroying jobs in one region while creating them elsewhere. These changes affect new forms of work and skills. At present, a decline is only expected for manual workers. These employees are chiefly employed in agricultural and industrial professions. On the other hand, with regard to intellectual and social tasks, a general increase in significance is expected, namely the increase in the importance of: (1) business skills, (2) selling and persuasion skills, and (3) serving and attending skills. The first two types of skills are interrelated because they are highly commercial in nature, while the anticipated increase in service and participation skills may be related to care tasks (Eurofund, 2019).

Technological development, including the popularisation of the Internet, has an increasing impact on the development of an individual's social competencies. It is not just a way of communication or a source of information, but also allows the construction of an information society, i.e., one that can employ modern technologies to improve quality of life. However, this phenomenon has two sides. Access to the Internet is now not only a facilitation, but sometimes a necessary condition for full participation in social, cultural and professional life. It is increasingly difficult for individuals to fully function in the social space without using this tool. As a result, part of society remains - for various reasons - on the margins of these changes, which leads to the emergence of a 
phenomenon called "digital exclusion" (e-exclusion).

Digital exclusion may result not only from lack of individual access to technology, but also from the lack of skills or the ability to use technology, which leads to social exclusion or no access to jobs. Initially, digital exclusion and the digital divide focused on computer access and the ability to use it. Due to the fact that understanding digital exclusion has evolved over the years, the scope of the discussion has changed from access to computers to acquiring skills and abilities to understand that limited access to the Internet is one aspect of digital exclusion that can lead to social exclusion (van Dijk, 2013). The concept of digital exclusion is a common research problem, but it has not yet been sufficiently researched. A significant aspect of this research is to examine important factors leading to the unequal access and use of ICT. The literature points out that the digital divide integrates technical, social and motivational aspects resulting from different approaches to digital exclusion.

The aim of this article is to analyse the causes and effects of technological exclusion on the European Union labour market. This will enable finding an answer to the research questions, to what extent does the phenomenon of digital exclusion occur in the EU, and what are its causes and consequences? Therefore, a literature review based on the critical literature analysis method will be carried out, followed by an analysis based on documents and statistical databases (descriptive analysis of secondary data).

The article's structure includes four sections apart from the introduction. In the first section, a review of literature on the causes and consequences of digital exclusion will be carried out. Next, the research methodology and data sources will be described. In the third section the results of the research analysis based on data from the Digital Economy and Society Index (DESI) and Eurostat will be presented. In the following section, the results of the analysis will be discussed and, subsequently, the most important conclusions will be summarised.

\section{Literature Review}

The term "digital exclusion" refers to the concept of "social exclusion" understood as the lack of access to certain goods necessary for normal functioning in society. It was formulated in the 1970s as a reflection of the multidimensionality of social life. In general terms, social exclusion may concern work, consumption, participation in culture, life of local communities, and politics (Haddon, 2000). Although the concept of digital exclusion first appeared in relation to technological disparities between developed and developing countries, in developed Western capitalist societies, the supranational goal of these debates quickly changed into the issue of technological inequalities in individual countries.

The uneven spread of new technologies has contributed not only to digital exclusion, but also to the digital divide. According to the OECD definition, the digital divide is a phenomenon of social inequality, or even the creation of a gap between individuals, households, enterprises and regions with different levels of socio-economic development related to access and use of information and communication technologies in all spheres of economic activity (OECD, 2001). In addition, the literature also introduces the term "information and communication poverty" (Tomczyńska, 2017). General concerns about 
"information inequality" appeared in public and political debate in the 1990s (Selwyn, 2004). Political and popular concepts of the digital divide are usually dichotomous either you have access to ICT or you do not. From this perspective, the digital divide is easy to define and, as a result, overcome (Edwards-Johnson, 2000). It is usually conceptualised by the dominant logic of goods, the division of which entails the delivery of digital goods to vulnerable groups of the population. Srivastava and Shainesh (2015) postulate an alternative dominating logic in services featuring a division of knowledge, e.g. health care and education. Differences in the level of services consumed by different people are a key aspect of the current digital divide.

In literature, other ways to deflate the phenomenon can be found. Digital exclusion is identified with systemic differences in the access and use of modern technologies between individuals that differentiate education, income, occupation, place of residence and different stages of life (Helsper, 2012). Castells (2001), for whom digital exclusion is a division between individuals, enterprises, institutions, regions and societies possessing material and cultural conditions for functioning in the digital world, yet unable to adapt to the fast pace of changes, is an even more complex deflation. Bearing in mind the above theoretical assumptions, it is stated that the concept of the digital divide does not cover the entire spectrum of the phenomenon. It does not take into account the extent to which ICT is employed by users, neglects the level of digital competence, the existence of the necessary infrastructure, and the importance of social, economic, organisational and cultural factors. In connection with the above, it should be assumed that the term "digital exclusion" is more adequate.

Moreover, the "digital exclusion" is described as a multidimensional phenomenon (CruzJesus, Oliveira, \& Bacao, 2012; van Dijk, 2013; Zhao, Collier, \& Deng, 2014). The first dimension is "motivational exclusion", which refers to mental barriers and aversion towards new technologies, which principally include: lack of faith in one's own abilities, lack of motivation and willingness to learn about modern technologies, and fear of new products. The second dimension - material exclusion - is associated with the common understanding of digital exclusion, i.e. the lack of the possibility of purchasing devices, software and network access services. The third dimension concerns skills and is understood as the lack of the ability to acquire, maintain or update ICT-related skills. Finally, the fourth dimension "use", which means that technology is used for a specific purpose. The individual dimensions of digital exclusion follow one another and the process is repeated as new technologies appear. Helsper (2012) proposed a theoretical model that assumes that specific areas of digital and social exclusion affect one another. These areas relate mainly to similar (economic, cultural, social, personal) resources. The model also proposes that digital exclusion is defined through access, skills and basic or motivational aspects.

Analysing reasons for digital exclusion, it can be pointed out that they evolve along with technological progress. According to research carried out 15 years ago, by order of the European Commission, the causes of digital exclusion included (EC, 2005):

- the unavailability of a PC at home, combined with lack of access at work or at Public Access Points,

- the high cost of PC ownership and Internet connection,

- the complexity of the technology and lack of basic skills, 
- lack of awareness,

- lack of time,

- language barriers, and

- unavailability of useful content.

However, recent research shows that the reason for digital exclusion is not due to the lack of access to a computer or the Internet, but above all the lack of skills and ways to use it. For example, people belonging to groups with lower access to the Internet and in which fewer people use it usually have much lower skills and use the Internet in a less comprehensive way, i.e. mainly as a source of entertainment and not as a tool to improve their own life situation. The digital threat concerns less educated people, especially older ones. Difficulties are also faced by people living in smaller towns and earning lower incomes per household. On the other hand, better-educated Internet users from larger towns and richer families, use the Internet in a more instrumental way (Batorski, 2014). Van Deursen and Helsper (2015), in their research, also indicated that the Internet remains more beneficial for people of higher social status, not in terms of how much they use technology, but what they achieve as a result.

Another study showed that people adjusting to technological change were driven by utilitarian effects, hedonic results (i.e. play) and social results (i.e. status) (Venkatesh, 2001). However, non-adaptable people were under the influence of rapid changes in technology and the fear of aging. Demographic factors, age and education are still significant predictors of Internet use (Laukkanen, 2016). Based on the literature review, it can be concluded that the problem of digital exclusion is complex and multilevel. Digital exclusion is not just an issue of social inequality. Digital inequality and deficit of competencies have a wider significance for the competitiveness of the economy, as it generates a stay for more technologically advanced products and services, as well as for increasing the competencies necessary on the labour market.

Taking into account rapid technological changes, it is necessary to analyse not only the reasons, but also the consequences of the progressive development of the labour market. The current debate on digital inequalities focuses mainly on the measures and not on the purposes of using ICT. The conceptualisation of the digital divide should, however, combine issues of access to and use of technology with the consequences of involvement in ICT for individuals. The effects of accessing information, resources and services via ICT are not uniform for all users. An important element is therefore understanding the consequences or potential consequences of ICT use by people (Selwyn, 2004). Thus, the impact of ICT can be analysed in terms of the extent to which technology makes it possible for individuals to participate in and be part of society, i.e. the extent to which ICT increases our ability to fulfill active roles in society, and where lack of access to them is a barrier (Haddon, 2000).

Digitisation transforms existing jobs, requiring new skills to perform new tasks, which may mean that the current workforce should be reclassified or replaced by employees already possessing these skills. In addition, digitisation contributes to the creation of new jobs, while other jobs are rendered unnecessary. There are numerous studies in literature on the subject that estimate the creation of jobs and job destruction resulting from digitisation in traditional enterprises and industries. The results are highly diverse and depend on the methodology used as well as the countries studied (EESC, 2017; IFR, 
2017). According to EESC (2017), digitisation is likely to contribute to the polarisation of the labour market. Particularly low- and middle-skill jobs are considered prone to automation. Digital skills will be highly sought after on future labour markets, similar to entrepreneurial skills and creativity. Owing to the right skills, people are prepared for good quality work and can use their potential as confident, active citizens. In a rapidly changing global economy, skills largely determine competitiveness and the ability to drive innovation (EC, 2016). They are a factor attracting investments and a catalyst for creating jobs and growth. That means that they are also the key to social cohesion.

\section{Materials and Method}

The purpose of this article is to determine the causes and effects of technological exclusion on the European Union's labour market. The research analysis will be based on the analysis of secondary data contained in Eurostat and the Digital Economy and Society Index (DESI). This index was introduced in 2014 for the purpose of studying the development of processes and directions of digitisation in EU countries. It is an aggregate indicator consisting of 30 component indicators characterising the availability of digitisation, its use by economic entities (enterprises and institutions) and individual users (households), the ability and frequency of employing digital solutions at school, work and home, as well as in professional and private life. This index covers five basic areas (Table 1).

Table 1. The five dimensions of the DESI

\begin{tabular}{|l|l|l|}
\hline No. & Dimensions of DESI & Specification of dimensions \\
\hline 1 & Connectivity & $\begin{array}{l}\text { Fixed broadband, mobile broadband, fast and ultrafast } \\
\text { broadband and prices }\end{array}$ \\
\hline 2 & Human capital & Internet user skills and advanced skills \\
\hline 3 & Internet use & Citizens' use of Internet services and online transactions \\
\hline 4 & Integration of digital technology & Business digitisation and e-commerce \\
\hline 5 & Digital public services & e-Government and e-health \\
\hline
\end{tabular}

Source: DESI (DESI, 2019b).

Bearing in mind the research goal on the labour market, the analysis mainly concerns the digital skills of employees. The Eurostat database contains several indicators providing information on the level of specific employee skills, measured by self-assessment, digital skills as part of the Community survey on the use of ICT in households and by individuals. The time range of the analysis was determined by access to the most current data, mostly from 2019. Interpretations have been developed owing to an in-depth comprehensive review of various studies.

The choice of method of analysing existing data was made on the basis of a set of secondary data evaluation criteria such as: methodology, accuracy, date of data collection, purpose of data collection, data content (Crowther \& Lancaster, 2008). The use of secondary data analysis to identify causes and exclusions in the EU is the right approach for a number of reasons. First of all, these data include extensive research in all EU countries. It should be emphasised that the high sample size, representativeness and 
number of observations provide sufficient information to assess the external validity of the data. Secondly, existing data allow for re-testing under the same conditions and according to a predetermined pattern, thus creating the possibility of replication. This is particularly important for ensuring the reliability of research analyses (Crowther \& Lancaster, 2008; Easterby-Smith, Thorpe, \& Lowe, 2002).

Despite many advantages, literature often indicates that results from secondary data analyses have limitations, namely that the information is too general and can rarely be directly used to solve specific problems (Beck, 2018). It should be emphasised that the use of secondary data analysis method in this article is justified as it allows identifying the level of digital exclusion in EU countries. On this basis, an attempt will be made to find an answer to the key research question, which is to what extent the phenomenon of digital exclusion in the EU occurs and what are the reasons and consequences?

\section{Results}

\subsection{The current state of digitisation development in EU countries}

In analysing the current level of digitisation in the EU, we can employ DESI, which is calculated as a weighted average of indicators from five areas: connectivity $(25 \%)$, workforce $(25 \%)$, Internet usage (15\%), technological integration $(20 \%)$ and digital public services $(15 \%)$. Each area is described by several of the 30 component indicators (Figure 1).

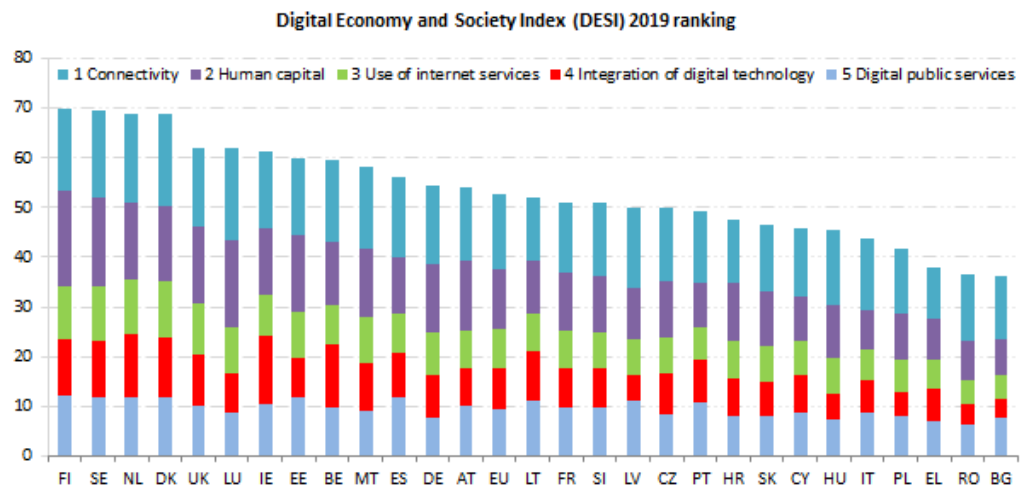

Figure 1. DESI indicators for EU countries in 2019

Source: DESI (2019b).

Taking into account these five areas, it can be concluded that differences between EU countries are noticeable primarily in the dimension of technological integration (using several digital technologies in a collective way), in the workforce and in the use of the Internet. In domestic terms, the DESI index of Finland, Sweden, the Netherlands and Denmark (over 68\% of weighted averages) is twice as high as in Bulgaria, Romania and Greece (below 39\%). For the European Union, the average result is $52.45 \%$, which means that most countries (15 countries) indicate a level below the EU average, and only 13 countries above the EU average. The biggest differences in the development of digitisation between the most advanced country (Finland) and the least advanced country 
(Bulgaria) in this ranking occur in relation to Human Capital, Internet Use and Integration of Digital Technology.

From the point of view of the labour market, the Human Capital area plays an important role, defining digital inclusion and skills, defined by two indicators: (1) Internet user skills and (2) advanced skills and development (Figure 2). The first is based on the European Commission's digital literacy index, which is calculated on the basis of the number and complexity of activities related to the use of digital devices and/or the Internet. The second includes indicators concerning the employment of ICT specialists and ICT graduates.

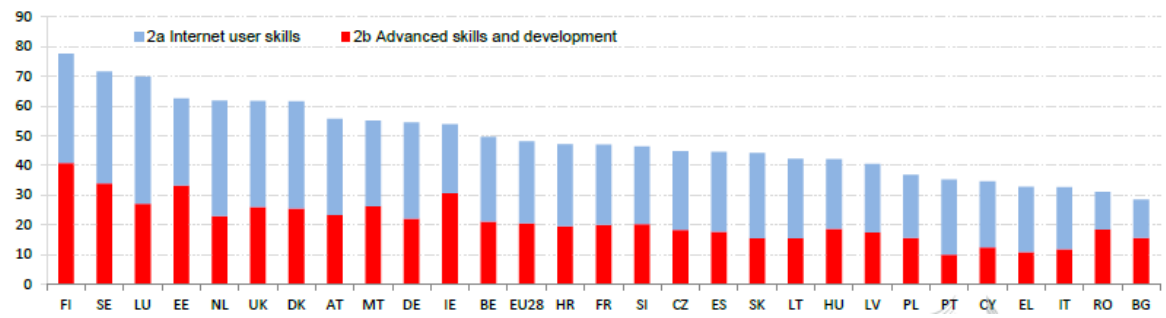

Figure 2. Human Capital Indicators according to DESI in EU countries in 2019

Source: DESI (2019a).

According to the latest data, Luxembourg, the Netherlands and Sweden have the best results in terms of Internet literacy, while Finland, Sweden and Estonia have the highest scores in terms of advanced skills and development. Bulgaria, Romania, Italy and Greece are ranked lowest in terms of the size of human capital according to DESI.

\subsection{Causes of digital exclusion due to lack of digital skills}

Digital skills are the key to combatting digital exclusion. Taking into account digital skills in individual EU countries (data unavailable for Italy), it can be noted that about $10 \%$ of the EU's workforce has no digital skills, chiefly because it does not use the Internet. In contrast, $35 \%$ lacks at least the basic digital skills currently required in most professions. The share of active workforce in the EU (employed and unemployed), which can be considered as lacking in digital skills (mainly because it does not use the Internet or does so rarely), is much higher in Member States such as Romania (26\%), Bulgaria (25\%) and Portugal (18\%), although they are among the ones showing the greatest improvement in this respect. Conversely, a large proportion of the workforce (between $82 \%$ and $89 \%$ ) in Member States such as Luxembourg, the Netherlands, Finland and Sweden have at least basic digital skills (Figure 3).

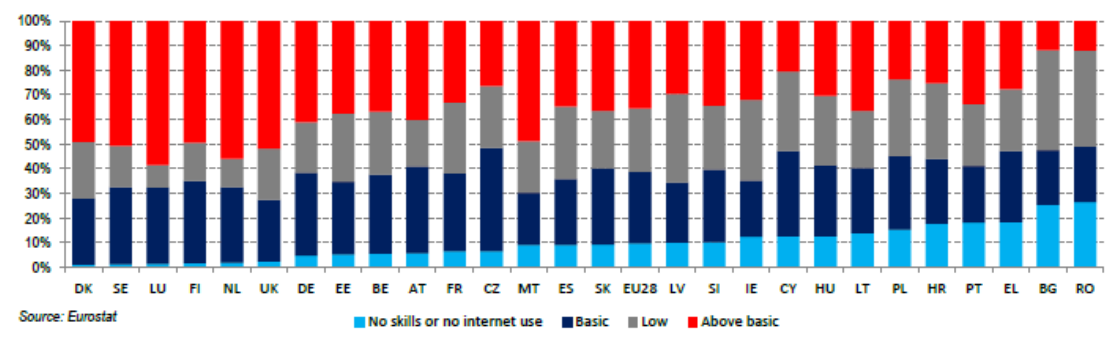

Figure 3. Digital skills of the EU labour force in 2017 (\% of individuals, by skills level) 
The analysed indicators present serious digital threats and exclusion from the labour market in the context of the rapid digitisation of the economy. The most common reasons for lack of access to the Internet at home are a lack of need or interest $(46 \%$ of households without Internet access in 2017), insufficient skills (43\%), and high costs of access and equipment (32\%). The impact of each of these factors varies greatly between Member States. For example, only $8 \%$ of Danish households without Internet access mentioned costs as a barrier, but up to $57 \%$ did so in Croatia and Hungary (DESI, 2019a).

The lack of appropriate skills remains by far the fastest growing factor discouraging employees from using the potential benefits of digitisation. This indicates a lack of motivation, which seems to be the greatest barrier to digital inclusion, especially for lowincome groups. The lack of motivation for using modern technologies can have various sources, such as lack of adequate knowledge on how to use the equipment and what opportunities the network can offer to users. A particularly important obstacle is the low level of knowledge about ICT, which influences the appearance of other negative phenomena: no need to use, inability to use and psychological problems, including fear and self-exclusion (manifesting itself in the "it's not for me" declaration) (Tomczyńska, 2017).

Another reason for digital exclusion may be different employee competences. The term "digital competences" includes a number of skills related to the use of modern technologies. Digital competences can be divided into the following skills: operational (e.g. activities necessary for operating a computer), information (e.g. searching, selecting, evaluating information), communication (e.g. e-mail, contacting, creating an online profile, issuing opinions), strategic (e.g. treatment of technology as a means for achieving personal and professional goals), creative (e.g. editing content according to personal preferences) (Jandric \& Randelovic, 2018).

Taking into account digital skills, it can be seen that there is a clear difference in the professional hierarchy. Managers, specialists, technicians and officials are intense ICT users at work, while use for workers is low. Hence, a large group of employees who either rarely or never use ICT coexists alongside an increasing number of employees for whom ICT is an integral part of their work. These two groups have very different work experiences, which can have a huge impact on career development, professional mobility and working life.

Other equally important factors possibly affecting the digital divide include, among others, age, education, income, location, culture, language, disability (van Dijk, 2013). Another reason for the exclusion of some users of the labour market may be inadequate technology design and organisational structure. Alternatively, technology can be seen as a tool to strengthen an organisation that not only supports employees, but also develops and transforms the work environment (Sims, Fusaro, \& Wolf, 2018). It should be added that the phenomenon of digital exclusion is also present in wealthier countries, although in a different form. Differences in access to new technologies in developed economies may be manifested on the same background, where other privileges of citizens are discriminated against. The most frequently mentioned aspects of digital exclusion are the 
division between women and men as well as division depending on age.

In conclusion, digital skills are essential not only for access to the labour market, but also for the benefits of the digital transformation currently under way. Ensuring that the EU's workforce has the necessary digital skills, including addressing the digital skill shortages in some groups, such as older people or manual workers, will therefore be indispensable for the creation of an inclusive digital economy and society.

\subsection{The consequences of digital exclusion for the labour market}

Undoubtedly, digital exclusion - as a new type of social exclusion of the $21^{\text {st }}$ century - is a phenomenon the consequences of which are perceived in many areas of life. Digitally excluded units are doomed to a worse position on the labour market, e.g. the lack of digital skills leads to a decrease in employees' competitiveness. Those who do not take advantage of ICT have less chance of finding a job or promotion in current ones, due to the lack of motivation and skills to improve their professional qualifications. In the context of digital exclusion on the labour market, it is important to indicate the possible effects on people which make it impossible to work or appear while looking for a job, but also which relate to work, remuneration, promotion, mobility and the possibility of changing jobs. Many jobs in traditional low-tech and medium-technology sectors do not require any digital skills. Current economic development forecasts for the EU indicate that the level of technological integration of enterprises in all sectors will grow and, in the case of high technology sectors, the technological leap may contribute to an increase in the level of digital skills. For example, in Denmark, Sweden (in 100\%) and Ireland (in 99.7\%), employees on the labour market are equipped with portable ICT devices and accessories, while in most EU countries this rate is below the EU average of 29.1\% (Figure 4).

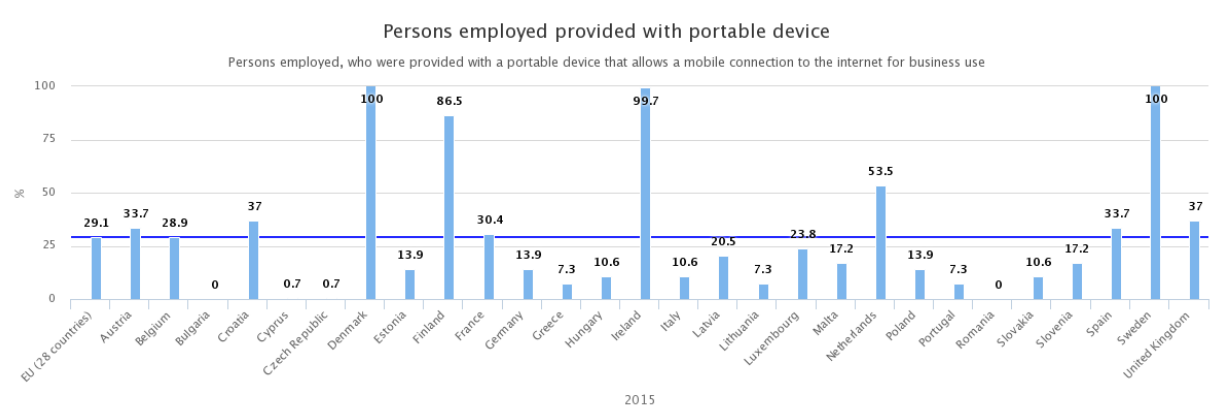

Figure 4. Employees provided with portable devices in 2015

Source: EC (2019).

To counteract existing disparities, in 2016 the European Commission published a new program called "Skills Agenda for Europe" to strengthen human capital and increase employability and competitiveness. This program presents a series of activities and initiatives to address the digital skills deficit in Europe. The new program aims to improve the quality of skill formation by increasing the comparability of skills and qualifications and enhancing professional development. As highlighted in in the program "A New Skills Agenda for Europe", the rapid digital transformation of the economy 
means that almost all jobs - as well as participation in society in general - require certain digital skills. Digitisation causes changes in business models, creating new opportunities and paths to obtain employment that require different types of skills.

Therefore, the situation in the EU requires broad measures to be taken. The lack of adequate literacy skills is a problem for 70 million Europeans, and an even larger number of them have very limited skills in mathematical reasoning and digital skills, which puts them at risk of unemployment, poverty and social exclusion. It is estimated that over half of the 12 million long-term unemployed are low-skilled (EC, 2016). The main problems, among other factors, are skill shortage and mismatch. Many people do jobs that are unsuited to their abilities. At the same time, $40 \%$ of European employers have difficulties finding people with the skills they need to develop and increase their innovation. Not enough people demonstrate the entrepreneurial attitude and skills needed to start their own business.

According to the basic assumption, the level of digital competences affects the widely understood level of participation in various areas of social life (van Dijk, 2005). The model of this impact has been operationalised in the form of five key areas of social life (van Deursen, van Dijk, \& van Helsper, 2014):

- economic - covering mainly issues related to employment and job search as well as the benefits of online shopping,

- social - covering the building of social ties and interpersonal communication and the related increase in social capital,

- political - involving, inter alia, participation in a political process (for example related to elections) or in non-institutional policy (for example in public debate on political issues) and civic participation,

- cultural - encompassing widely understood cultural activity as well as the sphere of education,

- institutional - including the use of public services and information, as well as medical services.

Considering the importance of technology for the labour market, it is extremely important to continuously search for ways to develop the digital divide and, as a result, digital exclusion. A careful look at the effects of the digital divide will help indicate the direction and speed of overcoming the digital gap. The effects of digital exclusion affect many aspects of social and economic development. We must remember that the electronic business environment sets completely new directions of action, carrying both opportunities and previously unknown threats.

\section{Discussion and Conclusions}

The digital economy is crucial for innovation, growth, employment and European competitiveness. The proliferation of digital technologies has a huge impact on the labour market and the types of skills needed in the economy and society. Digitisation changes employment structure, leading to the automation of "routine" tasks and the creation of new and different types of jobs. This drives demand for more qualified ICT specialists in all sectors of the economy. Demand for digital skills is noticeable in almost all occupations. For example, professions such as engineer, 
accountant, nurse, doctor, artist, architect and many others require an increased level of digital skills. The digital economy applies to every sector of industry and public service, profoundly affecting people's daily lives (Peppard \& Ward, 2016). Digitisation therefore leads to the fact that every citizen should have at least basic digital skills in order to be able to live, work, learn and participate in contemporary society. Digital skills are a basic condition of work and employment in a highly qualified economy. These skills are becoming more and more common.

The dynamics of the labour market is a very complex field dependent on many factors affecting the results, which makes it difficult to accurately determine causality and forecasting the consequences. However, in expert opinions on which tasks, jobs and industries will be most affected by automation, there is a general consensus that it must be necessary to equip current and future employees with skills allowing them to benefit from higher qualifications (and better paid ones) that result from automation, including robotics. At the same time, a clearer picture of low-skilled employment opportunities that will be created indirectly through technology-based innovation should be used to enable low-skilled workers who, for whatever reason, are unable to upgrade their skills to move to other sectors (IFR, 2017). The task of equipping current and future generations of employees with the opportunity to use the possibilities of automation rests both on the government and private sectors. The government must provide policies, incentives and programs to increase and retrain the workforce. Meanwhile, the private sector must invest more in skills training. The challenges of the modern era of globalisation, together with the fourth industrial revolution, create many opportunities and threats. Production automation, the digital revolution, robotisation, machine learning and further technological advances have a significant impact on the labour market and demand for digital competences, and digital skills.

The aim of this article was to analyse the causes and effects of technological exclusion on the labour market in the European Union, with particular emphasis on digital skills and labour market challenges in European countries. The results of the analysis show that the main reason for the limited development of the information society and thus the existence of the "digitally excluded" category is primarily a low level of digital skills, ineffective use of modern technologies, and lack of motivation. This means that digital exclusion should be treated in conjunction with other forms of social exclusion (nonInternet use is often associated with other forms of exclusion, such as low education, poverty or unemployment). The research results also show that the combination of skills needed in modern societies is becoming more complex and will evolve as a work environment with increased technological development, requiring future employees to develop digital skills and lifelong learning opportunities. Our findings are consistent with various recent empirical studies that have shown significant differences in real digital literacy among the population, depending on economic, educational, geographic and demographic differences (van Deursen \& van Dijk, 2011).

Based on the analysis, it can be concluded that the technological gap in EU countries may be reflected in various reasons (e.g. age, education, income level, location, culture, language), while the key to the market is the ability to use the Internet not only for entertainment purposes, but to improve one's social and professional position. It requires a change of attitude towards modern technologies, greater educational and 
professional activity, and undertaking economic activities on the labour market in the context of finding or creating sources of income and work.

Future research can focus on topics such as how companies can support the development of digital competences. It is possible to conduct further comparative tests to verify the correctness of existing indicators or to provide a more profound explanation of the research results. Further research may also focus on the possibilities and limitations of the fourth industrial revolution for the labour market, society and business, in order to provide a more in-depth understanding of the current challenges.

Funding: This research was funded by the Ministry of Science and Higher Education of the Republic of Poland within "Regional Initiative of Excellence" Programme for 2019-2022 (Project no.: 021/RID/2018/19).

\section{References}

Batorski, D. (2014). Polacy wobec technologii cyfrowych - uwarunkowania dostępności i sposobów korzystania. In J. Czapiński \& T. Panek (Eds.), Diagnoza spoteczna 2013: warunki i jakosśc syycia Polakón (pp. 357-384). Warszawa: Ministerstwo Pracy i Polityki Społecznej.

Beck, C. T. (2018). Secondary qualitative data analysis in the health and social sciences (1st ed.). London: Routledge,.

Castells, M. (2001). The Internet Galaxy: Reflections on the Internet, Business and Society. Oxford: Oxford University Press.

Crowther, D., \& Lancaster, G. (2008). Research Methods: A Concise Introduction to Research in Management and Business Consultancy (2ed ed.). New York: Taylor \& Francis.

Cruz-Jesus, F., Oliveira, T., \& Bacao, F. (2012). Digital divide across the European Union. Information \& Management, 49(6), 278-291.

DESI. (2019a). Human Capital - Digital Inclusion and Skills. Retrieved from https://ec.europa.eu/newsroom/dae/document.cfm?doc_id=59976

DESI. (2019b). The Digital Economy and Society Index. Retrieved from https://ec.europa.eu/digital-singlemarket/en/desi

Easterby-Smith, M., Thorpe, R., \& Lowe, A. (2002). Management Researcb: An Introduction. London: Sage.

EC. (2005). e-Inclusion revisited: The Local Dimension of the Information Society. Brussels: European Commission.

EC. (2016). A New Skills Agenda for Europe: Working together to strengthen buman capital, employability and competitiveness. $\operatorname{COM}(2016) \quad 381$ final. Retrieved from Brussels: https://ec.europa.eu/social/main.jsp?catId=1223\&langId=en

EC. (2019). Digital Transformation Monitor. Digital Transformation Monitor. Retrieved from https://ec.europa.eu/growth/tools-databases/dem/monitor/data-explorer/persons-employedprovided-with-portable-device

Edwards-Johnson, A. (2000). Closing the Digital Divide. Journal of Government Information, 27(6), 898-900.

EESC. (2017). Impact of digitalisation and the on-demand economy on labour markets and the consequences for employment and industrial relations. Brussel: European Economic and Social Committee.

Eurofund. (2019). Living and working in Europe 2015-2018. Luxembourg: Publications Office of the European Union.

Haddon, L. (2000). Social Exclusion and Information and Communication Technologies: Lessons from Studies of Single Parents and the Young Elderly. New Media \& Society, 2(4), 387-408.

Helsper, E. J. (2012). A Corresponding Fields Model for the Links Between Social and Digital Exclusion. Communication Theory, 22(4), 403-426.

IFR. (2017). The Impact of Robots on Productivity, Employment and Jobs. Frankfurt am Main: International Federation of Robotics.

Jandric, M., \& Randelovic, S. (2018). Adaptability of the workforce in Europe - changing skills in the digital era. Zbornike Radova Ekonomskog Fakulteta U Rijeci-Proceedings of Rijeka Faculty of Economics, 36(2), 757776. doi:10.18045/zbefri.2018.2.757 
Laukkanen, T. (2016). Consumer adoption versus rejection decisions in seemingly similar service innovations: The case of the Internet and mobile banking. Journal of Business Research, 69(7), 24322439.

OECD. (2001). Understanding the Digital Divide. Paris: OECD.

Peppard, J., \& Ward, J. (2016). The strategic management of information systems: Building a digital strategy (4th ed.). Chichester: Wiley.

Selwyn, N. (2004). Reconsidering Political and Popular Understandings of the Digital Divide. New Media Society, 6(3), 341-362. doi:10.1177/1461444804042519

Sims, J., Fusaro, M., \& Wolf, M. (2018). Digital Literacy And Exclusion In The Social Media Age. Paper presented at the UK Academy for Information Systems Conference Proceedings 2018.

Srivastava, S. C., \& Shainesh, G. (2015). Bridging the Service Divide Through Digitally Enabled Service Innovations: Evidence from Indian Healthcare Service Providers. Mis Quarterly, 39(1), 245-267.

Tomczyńska, W. (2017). Digital exclusion - defnicje, przyczyny, przeciwdziałanie. Adeptus, 10, 1-17. doi:10.11649/a.1503

van Deursen, A., \& Helsper, E. J. (2015). The Third-Level Digital Divide: Who Benefits Most from Being Online? In L. Robinson, S.R. Cotten, J. Schulz, T.M. Hale, \& A. Williams (Eds.), Communication and Information Technologies Annual: Digital Distinctions and Inequalities (Vol. 10, pp. 29-52). Bingley: Emerald Group Publishing Limited.

van Deursen, A., \& van Dijk, J. (2011). Internet skills and the digital divide. New Media \& Society, 13(6), 893911. doi:https://doi.org/10.1177/1461444810386774

van Deursen, A., van Dijk, J., \& van Helsper, E. (2014). Investigating Outcomes of Online Engagement. Media@LSEWorking Paper,28.

van Dijk, J. A. G. (2005). The deepening divide. Inequality in the information society. London: Sage.

van Dijk, J. A. G. (2013). A theory of the digital divide. In M. Ragnedda \& G. W. Muschert (Eds.), The digital divide: the internet and social inequality in international perspective (pp. 29-51). New York: Routledge.

Venkatesh, V. (2001). A Longditudinal Investigation of Personal Computers in Homes: Adoption Determinants and Emerging Challenges. MIS Quarterly, 25(1), 71-102.

Zhao, F., Collier, A., \& Deng, H. (2014). A multidimensional and integrative approach to study global digital divide and e-government development. Information Technology \& People, 27(1), 38-62. 